\title{
Avaliação macroscópica e microscópica de implante de Biomembrana em estômago de coelhos (Oryctolagus cuniculus)
}

\author{
[Macroscopic and microscopic evaluation biomembrane implant in the \\ stomach of rabbits (Oryctolagus cuniculus)] \\ A.R.S. Ferreira ${ }^{1}$, M.R.F. Machado ${ }^{2}$, V.S. Melo ${ }^{3}$, L.L. Martins ${ }^{4}$, \\ L.M. Leal $^{1}$, L.C.A. Sartori ${ }^{2}$ \\ ${ }^{1}$ Aluna de pós-graduação - Faculdade de Ciências Agrárias e Veterinárias - Unesp - Jaboticabal, SP \\ ${ }^{2}$ Faculdade de Ciências Agrárias e Veterinárias - Unesp - Jaboticabal, SP \\ ${ }^{3}$ Médico veterinário autônomo - Limeira, SP \\ ${ }^{4}$ Faculdade Ingá - Uningá - Maringá, PR
}

\begin{abstract}
RESUMO
Neste estudo foi implantado um retalho de biomembrana de látex natural em substituição a um fragmento da parede de estômago de coelhos albinos, raça Nova Zelândia, adultos, machos não castrados $(\mathrm{n}=12)$, com o intuito de avaliar o processo de reparação tecidual no que se refere à biocompatibilidade, à capacidade de reparação tecidual e a possíveis complicações. Aos 15, 30 e 60 dias de pós-operatório, os animais foram sacrificados, mediante o emprego de tiopental sódico (200mg $\mathrm{kg}-1$ ), para posterior avaliação macroscópica e análise histopatológica da interface do implante com o tecido nativo. Macroscopicamente, aos 15, 30 e 60 dias de pós-operatório observou-se presença de aderências na face serosa. Aos 60 dias de pós-operatório, em todos os animais avaliados, a biomembrana não foi encontrada. Sob microscopia de luz, aos 15 e 30 dias, verificaram-se descontinuidade das camadas muscular e mucosa, presença de infiltrado inflamatório polimorfonuclear. Foram visualizados vasos sanguíneos e fibras musculares. Aos 60 dias, as camadas mucosa, muscular estavam completamente reconstituídas. O implante foi biocompatível e forneceu arcabouço para orientação e desenvolvimento das camadas teciduais do estômago, mediante processos de reparação, restabelecendo a estrutura do órgão.
\end{abstract}

Palavras-chave: coelho, implante, membrana biológica, estômago

\begin{abstract}
In this study, biomembrane of natural latex was utilized to replace a section of the stomach wall of New Zealand rabbits, adult and non-castrated males $(n=12)$, in order to evaluate the tissue repair process in regards to its biocompatility, scar formation ability and possible complications. The animals were euthanized at fifteen, 30 and 60 days post operation, by use of sodium thiopental (200mg kg-1), followed by macroscopic and histopathological analysis of the implant interface with the native tissue. Macroscopically, at fifteen, 30, and 60 days post operation adherence was observed in the serosal wall. At 60 days post operation, the biomembrane is not in the stomach. Under light microscopy, at fifteen and 30 days, discontinuity of muscle layer and mucosa layer, and presence of polimorfonuclear population of inflammatory cells was observed. New vessels and muscle fibers were observed. At 60 days, the mucosa and muscle layers were complete reconstituted. The implants were biocompatible and had provided the mainframe for orientation and development of the tissue layers through repairing processes, thus reestablishing the organ structure.
\end{abstract}

Keywords: rabbits, implant, biological membrane, stomach

Recebido em 14 de setembro de 2012

Aceito em 17 de julho de 2013

E-mail: lescavonevet@yahoo.com.br 


\section{INTRODUÇÃO}

A utilização de membranas biológicas em Medicina Veterinária como implantes na substituição parcial e reconstrução de tecidos teve início com o trabalho de Pigossi (1967), que trabalhou experimentalmente com dura-máter homóloga de cães conservada em glicerina. A biomembrana de látex natural é extraída da Haevea brasiliensis, árvore popularmente conhecida como seringueira, e processada através de uma técnica de vulcanização diferente da convencional (Mrué, 1996; Mrué et al., 2004). Por ser de origem vegetal, esta não apresenta potencial de transmissão de doenças ao recepto (Pinho et al., 2004). Dentre os princípios do emprego de membranas originárias de diferentes espécies animais, assim como de implantes sintéticos, salienta-se a característica de fornecer arcabouço para orientação e desenvolvimento de novos tecidos, mediante processos de reparação que restabeleçam a estrutura e a função do órgão atingido (Batista et al., 1996), além de permitir aderência celular e estimular os vários tipos celulares, especialmente os polimorfonucleares envolvidos nos processos de cicatrização de feridas (Sousa et al., 2007). Dessa forma, objetivou-se avaliar o processo de reparação tecidual da Biomembrana quando implantada em substituição aos fragmentos da parede do estômago em leporinos, avaliando-se a biocompatibilidade, capacidade de cicatrização e possíveis complicações.

\section{MATERIAL E MÉTODOS}

Foram utilizados 12 coelhos albinos, raça Nova Zelândia, adultos, machos não castrados e com peso entre 2 e $2,5 \mathrm{~kg}$, que foram mantidos em gaiolas individuais, de dimensões de 80 x 50 x $35 \mathrm{~cm}$, localizadas no Biotério do Departamento de Morfologia e Fisiologia Animal da FCAVJUNESP, e receberam ração comercial, própria para a espécie, e água à vontade.

Para realização da técnica, posteriormente ao jejum alimentar e hídrico de 12 e 4 horas, respectivamente, cada coelho foi submetido à medicação pré-anestésica com acepromazina $1 \%$ $(1 \mathrm{mg} / \mathrm{kg})$ e butorfanol ( $1 \mathrm{mg} / \mathrm{kg})$, ambos por meio da via intramuscular (IM). Em seguida, a indução anestésica foi conduzida com a associação comercial de tiletamina e zolazepam (Zoletil ${ }^{\circ}$, Virbac), na dose de $10 \mathrm{mg} / \mathrm{kg}$ via intravenosa (IV), e mantida mediante emprego do anestésico volátil halotano, por meio de máscara conectada a um circuito semifechado. Com o animal posicionado em decúbito dorsal, foi realizada a tricotomia da região abdominal, seguida de antissepsia com iodopovidona degermante, álcool e iodopovidona. Durante o período transcirúrgico, realizou-se uma incisão pré-umbilical sobre a linha média ventral do abdômen, divulsão do tecido subcutâneo, abertura, em estocada, da musculatura abdominal sobre a linha alba, com seu posterior prolongamento cranial e caudal. Localizando-se o estômago, este foi isolado do restante da cavidade com compressas úmidas. Foram colocados dois pontos de reparo na extremidade cranial e dois na extremidade caudal do plano a ser incisado, para auxiliar e facilitar a manipulação do órgão (Stone, 1996), e, do ponto médio entre a curvatura maior e menor, no local de menor irrigação visceral, retirou-se um fragmento de $1,5 \mathrm{~cm}$ x $1,5 \mathrm{~cm}$, o qual se substituiu pela Biomembrana, de mesma dimensão (Fig. 1). Para fixação do implante ao órgão, utilizou-se sutura com fio absorvível sintético multifilamentar (Poliglactina 910) 5-0 em único plano. Fundamentado em Kropp (1998) e Nuininga et al. (2004), ao redor da interface do implante com o tecido nativo, foram fixados, transpassando as camadas seromuscular, quatro pontos simples e separados, com fio inabsorvível sintético monofilamentar (náilon) 3-0, para a identificação futura da região do implante.

No período pós-operatório, foram instituídas as terapias antimicrobiana, com sulfa-trimetoprim $(15 \mathrm{mg} / \mathrm{kg})$, via oral (VO), a cada 12 horas, durante sete dias consecutivos, e antiinflamatória, com flunexina-meglumina (1 $\mathrm{mg}$ $/ \mathrm{kg}$ ), via subcutânea (SC), a cada 24 horas, por três dias. Durante os sete dias subsequentes ao procedimento cirúrgico, avaliou-se clinicamente cada animal quanto ao aspecto da ferida cirúrgica, ao estado geral e ao aspecto da urina e das fezes e foi aferida a temperatura retal. Para serem efetuadas as avaliações macroscópica e histopatológica, nos tempos de 15, 30 e 60 dias pós-operatórios, em cada um desses períodos, quatro coelhos foram submetidos à eutanásia utilizando-se tiopental sódico $(200 \mathrm{mg} / \mathrm{kg}$ ) por via IV. Na avaliação macroscópica, investigou-se a região do implante quanto às seguintes ocorrências: aderências de órgãos, falha no enxerto, necrose, fístula, inflamação local, 
presença de líquidos na cavidade. Após avaliação macroscópica, fragmentos de aproximadamente $1 \mathrm{~cm}^{2}$, que continham a interface implante e tecido nativo, foram excisados, fixados em solução tamponada de formol a $10 \%$ e encaminhados ao Departamento de Morfologia e Fisiologia Animal da FCAVJ-UNESP para preparo histopatológico de rotina, com inclusão em parafina e coloração com Hematoxilina e Eosina (HE) e Tricrômico de Masson (TM). A pesquisa desenvolvida foi previamente aprovada pela Comissão de Ética e Bem-Estar Animal (CEBEA) da FCAVJUNESP, sob protocolo $n^{\circ}$ 009819-07, de acordo com os Princípios Éticos na Experimentação Animal, adotado pelo Colégio Brasileiro de Experimentação Animal (COBEA).

\section{RESULTADOS E DISCUSSÃO}

Durante a avaliação clínica diária, não se constataram alterações dignas de nota quanto ao estado geral dos animais, tampouco quanto ao aspecto da urina e das fezes. Esses achados assemelham-se às constatações de Sader et al. (2000), após implante de biomembrana de látex natural em pericárdio de cães. No presente estudo, em decorrência do emprego da biomembrana, assim como no experimento de la Fuente et al. (2003), não ocorreu nenhum caso de óbito.

Zimmermann e Raiser (2007) afirmaram que membranas de látex ocasionavam resposta imunológica local e rejeição quando empregadas em coelhos, uma vez que, sob avaliações histopatológicas, identificaram marcante presença de eosinófilos ao redor dos implantes, contraindicando, assim, o uso desse material nessa espécie animal. No entanto, nesta pesquisa, conquanto tenha se observado intenso infiltrado inflamatório de células, que a priori pareciam eosinófilos, constatou-se, por meio de mensurações, que esses tipos celulares tratavamse de pseudoeosinófilos (Banks, 1992), não caracterizando a ocorrência de reação imunogênica ao material implantado.

Observações semelhantes quanto à não ocorrência de reação imunogênica ao material implantado também foram exaradas por PotérioFilho et al. (1999) ao empregarem o biocompósito de látex no tratamento clínico de pacientes portadores de úlceras de membros posteriores, e também por Oliveira et al. (2007) ao utilizarem a biomembrana na substituição de fragmento da parede de bexiga em coelhos.

Embora a ocorrência de deiscências de sutura tenha sido constatada em ratos, nos quais o dreno de penrose fora utilizado nas anastomoses esofagogástricas (Cui et al., 2000), e também na mesma espécie, na recuperação de defeitos abdominais iatrogênicos através do uso de biomembrana (Paulo et al., 2005), em nenhum dos animais deste experimento tal fato foi observado.

Também não se notaram sinais macroscópicos de rejeição ou falha no implante, e, além disso, não foram verificados presença de muco, sinais de necrose, fístula, inflamação e líquidos nas cavidades (Smyrnis, 1982; Soares et al., 1996; Oh et al., 2002; Kung, 2002; de la FUENTE et al., 2003). Todavia, houve relato da ocorrência de fístula mediante emprego da biomembrana de látex natural na herniorrafia perineal em um cão (Paulo et al., 2005).

Em todos os animais avaliados, notou-se a ocorrência de aderências da área do implante com as seguintes estruturas: omento (todos os tempos), peritônio parietal da parede ventral do abdômen (todos os tempos), alças intestinais (15 e 30 dias de pós-operatório), fígado (15 e 30 dias de pós-operatório) e baço (15 e 30 dias de pósoperatório (Fig. 2A), achados estes que se assemelham, em parte, às descrições de Hori et al. (2001), em que encontraram aderência, entre o estômago e o omento, em cães nos quais realizaram implante de esponja de colágeno nesse órgão. As aderências pós-cirúrgicas que ocorrem são decorrentes de baixa atividade fibrinolítica no local da lesão cirúrgica, favorecendo o acúmulo de matriz de fibrina e, consequentemente, uma fibroproliferação, que se caracteriza por adesão (Liakakos et al., 2001). Em contrapartida, em apenas um animal do grupo, aos 30 dias de pós-operatório, não foram encontradas aderências do estômago com nenhuma estrutura, observação esta que corrobora os achados de Smyrnis (1982) ao utilizar "dracon patch" em estômago de coelhos. Está também de acordo com as observações relativas à utilização da biomembrana de látex natural em substituição a fragmento de pericárdio em cães (Sader et al., 2000); com as descrições de Mente e Ceneviva (2001), quando da 


\section{Ferreira et al.}

aplicação de látex no subcutâneo de ratos normais e diabéticos; e ainda com os relatos sobre o emprego da biomembrana como implante conjuntival (Pinho et al., 2004). Aos 60 dias de observação, a biomembrana não foi encontrada, nem na parede nem sequer no lúmen do estômago. Embora também não se tenha verificado a presença dessa estrutura nas fezes dos coelhos (Fig. 2B), acredita-se que tal ocorrência assemelhe-se às de Mrué (1996), que detectou o biocompósito nas fezes dos cães, após dez dias da esofagoplastia, e às observações de Paulo et al. (2005), que verificaram a eliminação do biopolímero, em média, aos 13,8 dias após sua implantação na parede abdominal ventral de ratos.

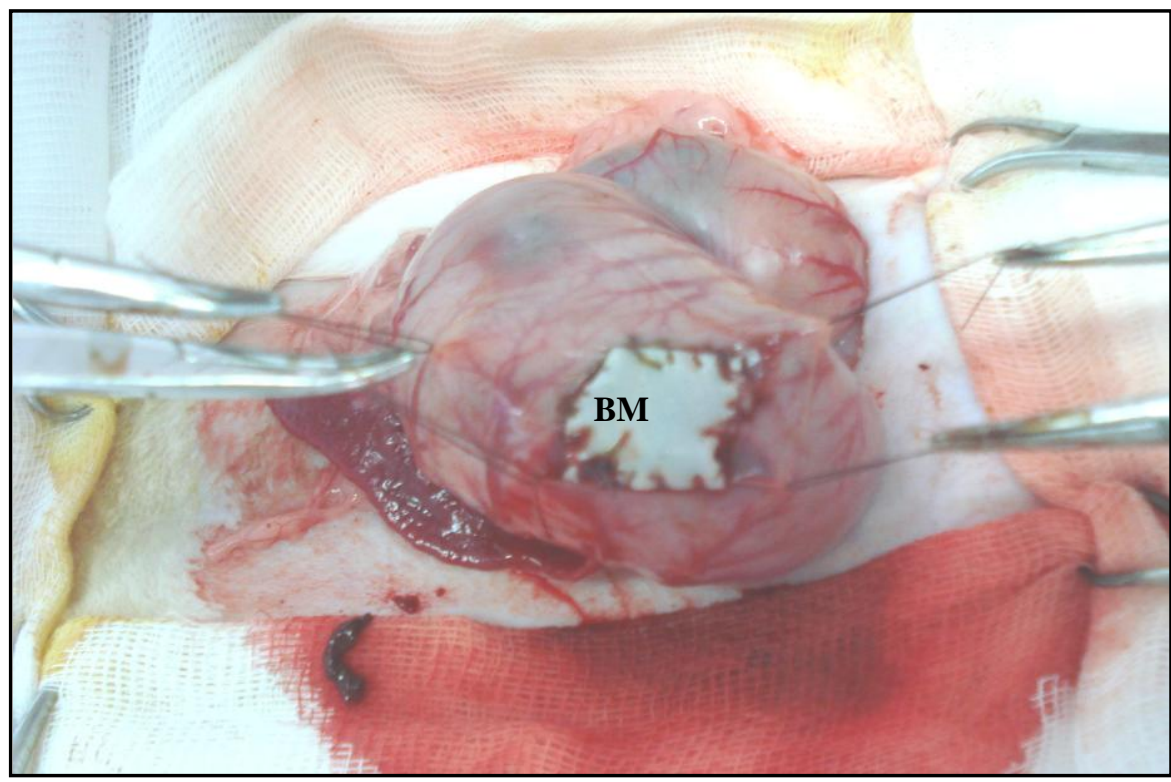

Figura 1. Fotografia do estômago de um coelho, macho, adulto, de raça Nova Zelândia. Em período transoperatório, em que se verifica o implante de biomembrana (BM) totalmente fixado à parede do estômago.

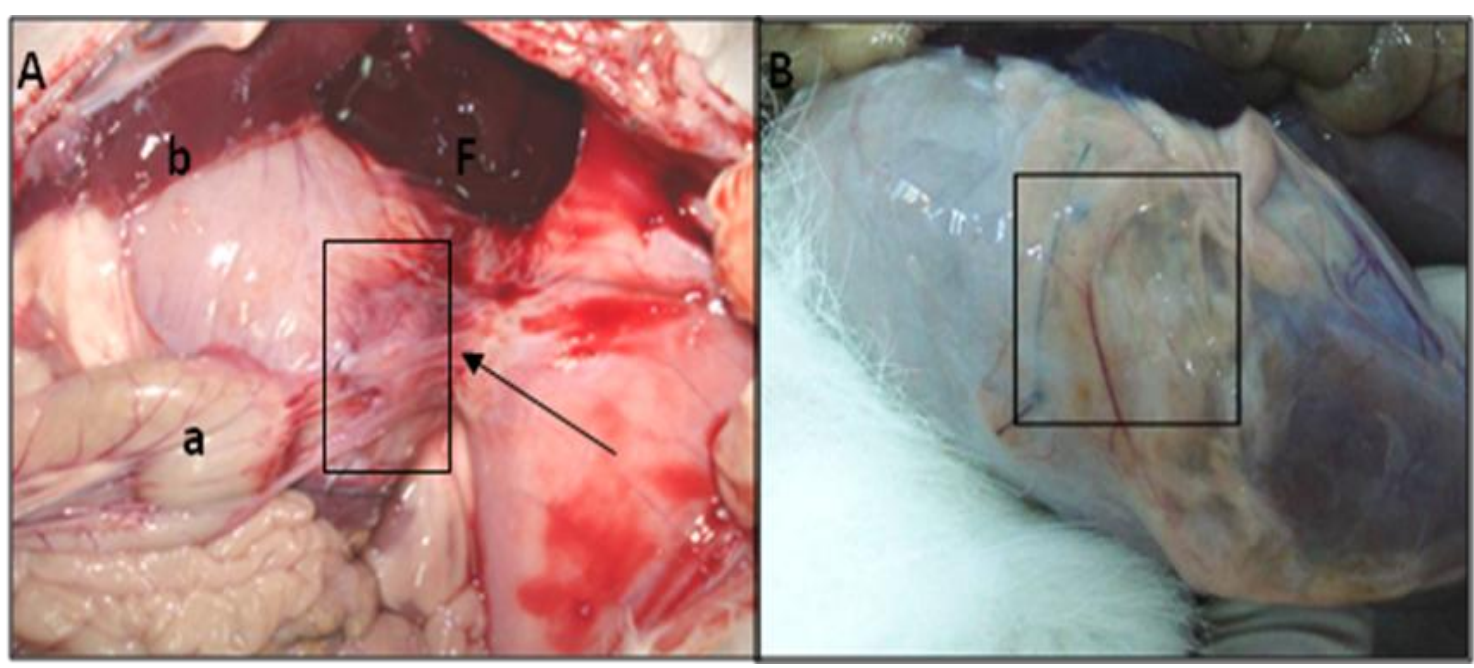

Figura 2. Fotografia da região ventral interna do estômago: Em A, aos 15 dias de pós-operatório, em que se observam aderências da área do implante (retângulo) com o peritônio parietal da parede ventral do abdômen (seta), alças intestinais (a), fígado (F) e baço (b); e em B, aos 60 dias de pós-operatório, em que se notam a área do implante totalmente integrado à parede do estômago e aderência ao omento (quadrado). 
$\mathrm{Na}$ análise histopatológica da interface do implante com o tecido nativo dos coelhos submetidos à eutanásia aos 15 dias de pós-operatório, observou-se descontinuidade da camada muscular e mucosa (Fig. 3A), achados que se assemelham às descrições de Soares et al. (1996), quando realizaram anastomoses esofagogástricas em cães; às de Sader et al. (2000), ao utilizarem o biopolímero em pericárdio de cães; às de Hori et al. (2001), após implantarem esponja de colágeno em estômago de coelhos; às de Mente e Ceneviva (2001), no implante de látex em subcutâneo de ratos normais e diabéticos; às de Oh et al. (2002), na utilização de PDX em estômago de cães; também às descrições de Frade et al. (2002), ao utilizarem a biomembrana em úlceras crônicas de pernas; e aos achados de la Fuente et al. (2003), ao aplicarem submucosa de intestino delgado de suínos em estômago de ratos. De outra forma, estes achados diferem dos registros de Smyrnis (1982), que constatou completa regeneração da mucosa e serosa após 15 dias de pós-operatório em estômago de coelhos com o uso de "dracon patch"; de Mrué (1996), que verificou a formação de todas as camadas esofágicas, em cães, após dez dias de implante da biomembrana como substituta parcial desse órgão; e de Pinho et al. (2004), que notaram epitelização conjuntival após cinco dias de implantação desse biocompósito na conjuntiva de coelhos. Aos quinze dias de pós-operatório, observou-se a presença de infiltrado inflamatório constituído por células polimorfonucleares (PMN) e mononucleares $(\mathrm{MN})$, resultados estes que estão de acordo com as descrições de Sader et al. (2000), que implantaram o biopolímero de látex na substituição parcial de segmento de pericárdio em cães; assemelham-se às constatações de Rabelo et al. (2005), ao utilizarem biopolímero de látex, em hérnias umbilicais de bovinos leiteiros; e coincidem, em parte, às descrições de Soares et al. (1996), ao realizarem em cães anastomoses esofagogástricas utilizando anel biofragmentável, além de sutura por invaginação, pois esses autores observaram a predominância de polimorfonucleares. Essas constatações sugerem a evolução do processo de reparação tecidual, caracterizado, nesse período, pelas fases de debridamento e proliferação (Ringler, 2000).
Nas amostras referentes aos implantes de biomembrana, dos coelhos eutanasiados aos 30 dias de pós-operatório, observadas à microscopia de luz, verificou-se descontinuidade das camadas mucosa e muscular (Oh et al., 2002; Frade et al., 2002; de la Fuente et al., 2003). Já para de Smyrnis (1982) ocorreu completa regeneração da mucosa e serosa, após 15 dias de pós-operatório, em estômago de coelhos, com o uso de "dracon patch", e Soares et al. (1996) observaram completa reepitelização em anastomoses esofagogástricas de cães, aos 30 dias de pósoperatório. Também discordam dos achados de Mrué (1996), que verificou a formação de todas as camadas esofágicas, em cães, após dez dias de implante da biomembrana como substituta parcial desse órgão. Diferem ainda dos relatos de Hori et al. (2001), ao notarem regeneração da parede do estômago aos 28 dias de pósoperatório, quando da utilização de esponja de colágeno em cães; de Mente e Ceneviva (2001), que, em implante de látex no subcutâneo de ratos normais e diabéticos, observaram epitelização aos 21 dias de pós-operatório; e de Pinho et al. (2004), ao notarem epitelização conjuntival após cinco dias de implantação desse biocompósito na conjuntiva de coelhos. Ainda aos 30 dias de pósoperatório, observou-se infiltrado inflamatório mononuclear e polimorfonuclear (Hori et al., 2001, Mente e Ceneviva, 2001; Rabelo et al., 2005) (Fig. 3B). Entretanto, tais verificações diferem das constatações de Soares et al. (1996), que não verificaram infiltrado inflamatório aos 30 dias de pós-operatório ao realizarem anastomoses esofagogástricas em cães.

Aos 60 dias de pós-operatório, verificou-se nos animais estudados que a parede do estômago, no local do implante, estava contínua, com todas as camadas reconstituídas, composta, a partir do lúmen, pelas seguintes camadas: mucosa, submucosa, muscular e serosa (Fig. 3C), de acordo com as descrições sobre a estruturação tecidual gástrica normal, pelos tratados clássicos de anatomia e histologia (Junqueira \& Carneiro, 2004), embora nas amostras em questão tenha se observado discreto infiltrado inflamatório mononuclear (MN) (Fig. 3D) ao se comparar com as observações dos períodos anteriores, achados estes que se assemelham às descrições de Rabelo et al. (2005). 


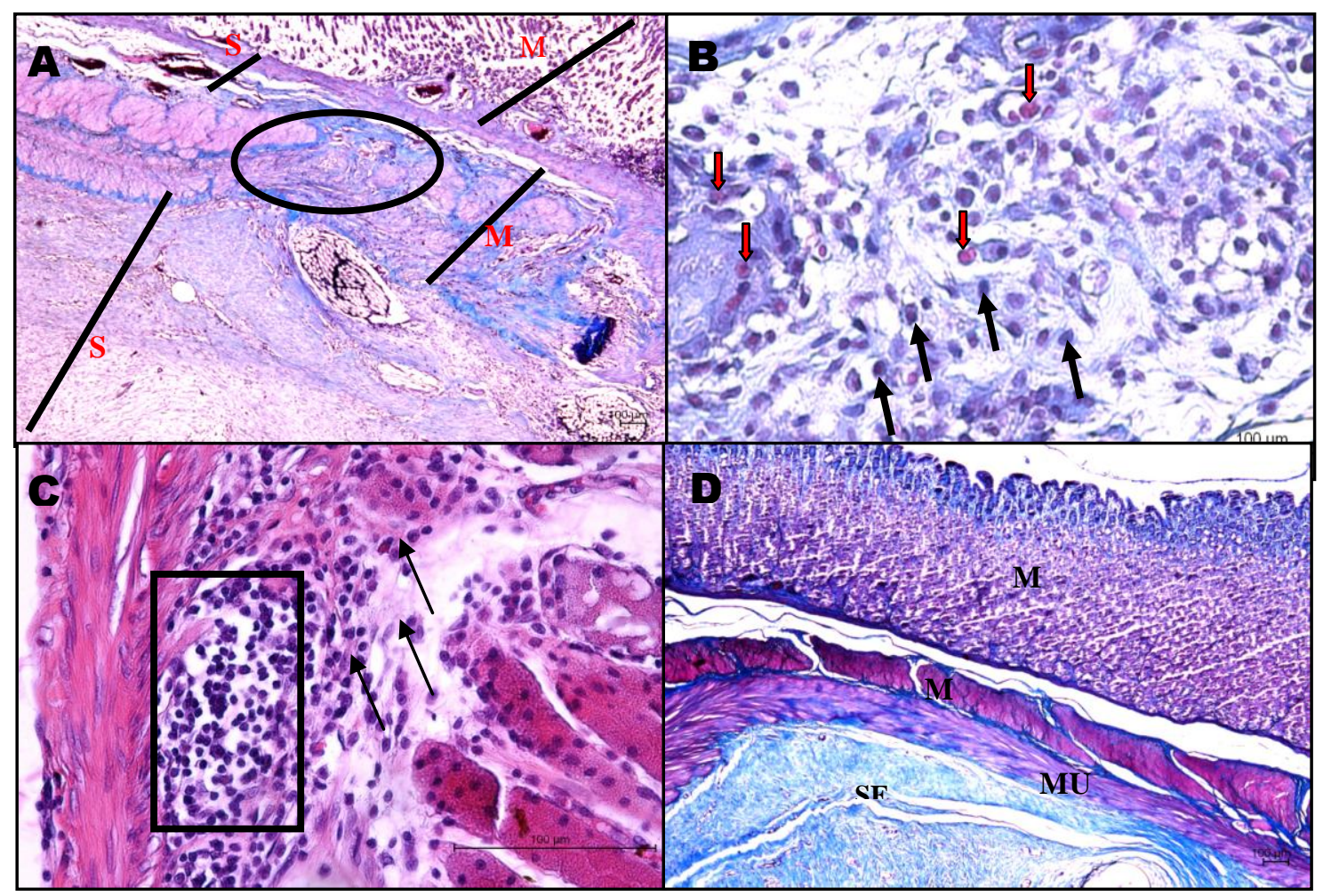

Figura 3. Fotomicrografias da região de gastrorrafias de coelhos, machos, adultos, da raça Nova Zelândia Branco: Em A, aos 15 dias de pós-operatório, em que se notam descontinuidade (círculo) da camada muscular (MU), mucosa neoformada e hiperplásica (M). Serosa (SE). Submucosa (S). Os traços estão delimitando cada camada do estômago (Paraplast, TM, 10X). Em B, aos 30 dias de pós-operatório, em que se nota infiltrado inflamatório polimorfonuclear, representado por pseudoeosinófilos (setas vermelhas) e mononuclear, representado por linfócitos (setas pretas) (Paraplast, TM, 40X). Em C, aos 60 dias de pós-operatório, em que se observou infiltrado inflamatório mononuclear difuso em submucosa (retângulo), representado por linfócitos (setas) (Paraplast, HE, 10X). Em D, aos 60 dias de pós-operatório, em que se observou que as camadas mucosa (M), muscular interna (MUi) e externa (MUe) apresentaramse completamente formadas. Camada serosa (SE) (Paraplast, TM, 10X).

Vale ressaltar que se constatou, em todos os tempos avaliados de pós-operatório, presença de neovascularização, fato que também foi observado em outras aplicações, sejam elas clínicas ou cirúrgicas, da biomembrana de látex natural (Mrué, 1996; Potério-Filho et al., 1999; Sader et al., 2000; Oliveira et al., 2003; Pinho et al., 2004; Paulo et al., 2005; Rabelo et al., 2005; Sousa et al., 2007). Essas observações sugerem a evolução do processo de reparação tecidual, caracterizado, nesse período, pelo início da fase de remodelação, que pode perdurar por meses e até um ano (Ringler, 2000).

\section{CONCLUSÕES}

Mediante os resultados obtidos, acredita-se poder concluir que a biomembrana de látex natural forneceu arcabouço para orientação e desenvolvimento de todas as camadas do estômago, por meio de processos de reparação, restabelecendo, aos 60 de pós-operatório, os tecidos que compõem o órgão, evitando também o escape de conteúdo estomacal para a cavidade. Associado a isso, os implantes foram biocompatíveis, uma vez que não induziram à reação imunológica de rejeição. 


\section{AGRADECIMENTOS}

À Fundação de Amparo à Pesquisa do Estado de São Paulo (FAPESP), pelas bolsas de mestrado concedidas (processo FAPESP número 05/52927-4).

\section{REFERÊNCIAS}

BANKS, W.J. Histologia veterinária aplicada. 2.ed. Manole LTDA. 1992. p.454-456.

BATISTA, L.C.; DALECK, C.R.; SHIMANO, A.C. et al. Estudo comparativo da resistência à tração do peritônio (bovino, eqüino, suíno e canino) a fresco e conservado em glicerina. Braz. J. Vet. Res. Anim. Sci., v.33, p.305-312, 1996.

CUI, Y.; URSCHEL, J.D. Latex rubber (penrose drain) is detrimental to esophagogastric anastomotic healing in rats. J. Cardiovasc. Surg., v.41, p.479-81, 2000 .

de la FUENTE, S.G.; GOTTFRIED, M.R.; LAWSON, D.C. et al. Evaluation of porcine-derived small intestine submucosa as a biodegradable graft for gastrointestinal healing. J Gastrointest Surg, v.7, p.96101, 2003.

FRADE, M.; CURSI, I.B.; ANDRADE, F.F. et al. Induction of the leg wound healing by natural latex biomembrane (NLB). Proceedings... Paris: Masson, 2002. Disponível em: <www.e2med.com/ad>. Acessado em: 26 abr. 2005.

HORI, Y.; NAKAMURA, T.; MATSUMOTO, K. et al. Experimental study on in situ tissue engineering of the stomach by na acellular collagen sponge scaffold graft. ASAIO Journal, v.47, p.206-210, 2001.

JUNQUEIRA, L.C.; CARNEIRO, J. Ap. Digestivo In___. Histologia básica. 10.ed. Rio de Janeiro: Guanabara Koogan, 2004. p.284-316.

KROPP, B.P. Small-intestinal submucosa for bladder augmentation: a review of preclinical studies. World $J$. of Urol., v.16, p.262-267, 1998.

KUNG, S.P. Surgical repair of giant gastroduodenal perforation with teflon-felt? Med Hypotheses, v.59, p.473-4, 2002.

LIAKAKOS, T.; THOMAKOS, N.; FINE, P.M. et al. Peritoneal adhesions: etiology, pathophysiology, and clinical significance. Recent Advances in Prevention and Management. Diges. Surg., v.18, p.260-273, 2001.

MENTE E.D.; CENEVIVA, R. - Transplante de ilhotas pancreáticas em dispositivo de imunoisolamento celular. Acta Cir. Bras., v.16, p.8487, 2001.
MRUÉ, F. Substituição do esôfago cervical por prótese biossintética de látex - estudo experimental em cães. 1996. 109f. Dissertação (Mestrado em Cirurgia) - Faculdade de Medicina de Ribeirão Preto, Universidade de São Paulo, Ribeirão Preto.

MRUÉ, F.; COUTINH-NETTO, J.; CENEVIVA, R. et al. Evaluation of the biocompatibility of a new biomembrane. Materials Rese., v.7, p.277-283, 2004.

NUININGA, J.E.; MOERKERK, H.; HANSSEN, A. et al. A rabbit model to tissue engineer the bladder. Biomaterials, v.25, p.1657-1661, 2004.

OH, D.S.; MANNING, M.M.; EMMANUEL, J. et al. Repair of full-thickness defects in alimentary tract wall with patches of expanded polytetrafluoroethylene. Ann. Surg., v.35, p.708-11, 2002.

OLIVEIRA, J.A.A.; HYPPOLITO, M.A.; COUTINHO-NETTO, J.; MRUÉ, F. Miringoplastia com a utilização de um novo material biossintético. Rev. Bras. de Otorrinolaringologia, v.89, p.649-655, 2003.

OLIVEIRA, T.C.; SCAVONE, A.R.F.; MACHADO, M.R.F.; MAZZUCATTO, B.C. Cistoplastia experimental em coelhos (Oryctolagus cuniculus) com peritônio bovino conservado em glicerol a $98 \%$. Cienc. Rural, v.38, p.2218-2224, 2007.

PAULO, N.M.; LIMA, F.G.; SIQUEIRA JÚNIOR, J.T. et al. Membrana de látex da seringueira (Hevea brasiliensis), com e sem polilisina a $0,1 \%$ e tela de marlex na reconstrução de defeitos iatrogênicos da parede abdominal de ratos. Acta Cirúrg. Bras., v.20, p.305-310, 2005a.

PAULO, N.M.; SILVA, M.A.M.; CONCEIÇÃO, M. Biomembrana de látex natural (Hevea brasiliensis) com polilisina a $0,1 \%$ para herniorrafia perineal em um cão. Acta Scie. Vet., v.33, p.79-82, 2005b.

PIGOSSI, N. Estudo experimental e clínico sobre o emprego, como implante, da dura-máter homógena conservada em glicerina à temperatura ambiente. Rev. da Assoc. Méd. Bras., v.17, p.263-278, 1967.

PINHO, E.C.C.M.; SOUZA, S.J.F.; SCHAUD, F. et al. Uso experimental da biomembrana de látex na reconstrução conjuntival. Arq. Bras. de Oftal., v.67, p.27-32, 2004.

POTÉRIO-FILHO, J.; SILVEIRA, S.A.F.; POTÉRIO, G.M.B. et al. O uso do latéx natural com polilisina $0,1 \%$ na cicatrização de úlceras isquêmicas. In: CONGRESSO BRASILEIRO DE ANGIOLOGIA E CIRURGIA VASCULAR, 33., 1999, Belo Horizonte. Anais... Belo Horizonte: Sociedade Brasileira de Angiologia e Cirurgia Vascular, 1999. p.156. 
RABELO, R.E.; SANT' ANA, F.J.F.; PAULO, N.M. et al. Emprego do compósito látex, poliamida e polilisina a $0,1 \%$ na correção cirúrgica de hérnias umbilicais recidivantes em bovinos leiteiros. Acta Scient. Vet., v.33, p.169-175, 2005.

RINGLER, D.J. Inflamação e reparo. In: JONES, T.C. et al. Patologia Veterinária. São Paulo: Manole, 2000. cap.5, p.119-165.

SADER, S.L.; COUTINHO-NETTO, J.; BARBIERI NETO, J. et al. Substituição parcial do pericárdio de cães por membrana de látex natural. Rev. Bras. de Cirurg. Cardiov., v.15, p.338-344, 2000.

SMYRNIS, S.A. Dacron patch for closure of experimental stomach defects. Br. J. Sur., v.69, p.823, 1982.
SOARES, J.H.; NIGRO, A.J.T.; LIMA, C.A.P. et al. Anastomoses esôfago-gástricas com anel biofragmentável e por invaginaçäo: estudo experimental em cães. Acta Cir. Bras, v.11, p.191-9, 1996.

SOUSA, L.C.A.; PIZA, M.R.T.; NETTO, J.C. et al. Biomembrana de látex: novo método para o revestimento da cavidade aberta nas timpanomastoidectomia. Rev. Bras. Otorrinolaringol., v.73, p.331-336, 2007.

STONE, E.A. Bexiga. In: BOJRAB, M.J. Técnicas atuais em cirurgia de pequenos animais. 3.ed. São Paulo: Roca, 1996. p.355-356.

ZIMMERMANN, M.; RAISER, A.G.; BARBOSA, A.L.T. et al. Teste de biocompatibilidade e resistência de membranas de látex em cães. Cienc. Rural, v.37, p.1719-1723, 2007. 